American Journal of Pharmaceutical Education 2019; 83 (10) Article 7784.

\title{
COMMENTARY
}

\section{The Critical Role of Self-Compassion and Empathy in Well-Being}

\author{
Daniel R. Malcom, PharmD ${ }^{\mathrm{a}, \mathrm{b}}$ \\ ${ }^{a}$ Sullivan University College of Pharmacy and Health Sciences, Louisville, Kentucky \\ ${ }^{\mathrm{b}}$ Associate Editor, American Journal of Pharmaceutical Education, Arlington, Virginia \\ Submitted August 1, 2019; accepted August 8, 2019; published December 2019.
}

Keywords: self-compassion; compassion; empathy; education; well-being

In mid-2019, I engaged with the health care system as a patient in a rather unexpected and significant way. Despite my experience as a health care professional, nothing prepared me for being powerless and at the mercy of my own body. I felt mentally frustrated, confused, frightened, and vulnerable. In the pit of my negative emotions, a hand (both metaphorically and literally) reached out to grasp mine and tell me that it was understandable how powerless I felt. That hand was connected to a person who stepped out of her role as a health care provider and got down into the pit with me to acknowledge the value of my feelings and show me that there was a way out. She encouraged me to not lose or abandon my connection with those around me and recognize that I am a person and worthy of compassion and respect not only from others, but most importantly from myself.

An eye-opening activity I completed in therapy soon after this experience involved a simple mirror as a prop. I was asked to look in the mirror and explain what (and who) I saw in my reflection. Immediately, I began to describe all the flaws I perceived in the person staring back at me. The therapist acknowledged my feelings and my experience of what I saw, but told me that who I described was not the person she saw in front of her. Her description involved an equally detailed analysis but focused instead on positive attributes. It was in that moment I realized that my self-evaluations and reflections never acknowledged the successes I had had, but rather only the failures and times I had fallen short of goals. Mirrors have always had an important role in psychology and our understanding of the concept of sentience, which includes the subjective experiences of feeling emotions and understanding reason. An animal acknowledging that the reflection in the mirror is, in fact, not a different entity altogether has been identified as a sign of advanced intelligence. ${ }^{1}$ Yet, in this example, I failed the mirror test in a way by only seeing a fraction or small part of myself in

Corresponding Author: Daniel Malcom, Sullivan University College of Pharmacy, 2100 Gardiner Ln., Louisville, KY 40205. Tel: 502-413-8969. Email: dmalcom@sullivan.edu. my reflection. Each act of looking into a mirror has since become a mini-opportunity to check my own vision of who I see and how I fit into humanity.

I experienced firsthand the profound impact of selfcompassion and empathy, seemingly logical concepts I thought I understood intellectually but had never previously needed at such a deep personal level. Compassion for others has been widely recognized as an integral part of patient-centered care. ${ }^{2-5}$ Patients who perceive a lack of empathy and compassion in their care sue for malpractice at a higher rate, are less likely to return for care, and have poorer clinical outcomes. ${ }^{3,5}$ I have witnessed patients in my care unexpectedly pass away, receive terminal diagnoses, or be faced with seemingly insurmountable physical challenges. In these situations, I have been intentful in showing compassion and empathy for them and their loved ones, understanding that their suffering and resilience give them strength. Rarely, however, have I had the insight to turn those feelings around on myself and evaluate my own actions, choices, and experiences as a part of the broader experience of humanity. While compassion for others is celebrated as a virtue, selfcompassion is often incorrectly equated with self-esteem (which involves feeling good about the way others see you) and viewed as selfish or overly self-centered. ${ }^{6}$ This image of self-compassion as a negative or undesirable character trait must be changed.

Neff defined self-compassion as a person "actively encouraging the expression of warmth, concern, and caring toward the self," and developed the "Self-Compassion Scale" (SCS) for individuals to evaluate their own levels of self-compassion. ${ }^{6,7}$ The 26-item SCS contains six subscales, including self-kindness, self-judgment, common humanity, isolation, mindfulness, and over-identification. Higher values on this scale equate to higher levels of selfcompassion. Inspiration for many of the elements included in this scale stem from Buddhist psychology, which has long included a focus on how individuals view their own experiences within the context of common humanity. ${ }^{6}$ While Neff's scale has been used extensively, there is some 


\section{American Journal of Pharmaceutical Education 2019; 83 (10) Article 7784.}

debate in the literature regarding the various domains of self-compassion as well as how closely it relates conceptually to compassion for others. ${ }^{2,8}$ More recent works have explored the significance of self-compassion in various health care professionals including nurses, physicians, and clinical psychologists, among others. ${ }^{9-11}$ No studies to date have assessed self-compassion in pharmacists, pharmacy faculty members, or student pharmacists, so more work in this area is needed.

Author Brené Brown has researched the concepts of shame and empathy extensively and written multiple best-selling books on the subjects. In Rising Strong: How the Ability to Reset Transforms the Way We Live, Love, Parent, and Lead, Brown describes compassion and empathy for others within the context of exploring those traits within ourselves:

In cultivating compassion, we draw from the wholeness of our experience - our suffering, our empathy, as well as our cruelty and terror. It has to be this way. Compassion is not a relationship between the healer and the wounded. It's a relationship between equals. Only when we know our own darkness well can we be present with the darkness of others. Compassion becomes real when we recognize our shared humanity. ${ }^{12}$

Holding the mirror to ourselves (metaphorically or literally) and evaluating our own experiences can be painful and may seem counterproductive to improving the quality of care we provide our patients and education we provide our students. It requires vulnerability, which can induce feelings of uncertainty and even shame. But we must recognize that our mistakes and failings are not "special" or different than those we allow others to have when we show compassion. Our shortcomings make us a part of humanity rather than separate from it, despite how we may view them.

An overall sense of well-being begins with how we view and care for ourselves as human beings, full of emotions, thoughts, passions, and flaws that make us unique as well as link us to others. Any concept of "self-care" must have as its core the idea that we as people deserve and are worthy of the opportunity to care for ourselves. As faculty members, practitioners, and mentors, we must embrace the importance of taking care of our own mental health (as well as physical health), setting an example for those around us and removing the stigma of self-compassion and empathy. Seeking professional mental health resources should not be interpreted as a sign of weakness, but instead as an everyday part of wellness, much as regular checkups with a primary care physician or annual physicals are viewed. Everyone experiences feelings of pain, loneliness, despair, and inadequacy, but it is only in sharing these as a part of our common humanity that we can shine light on them and understand that we are not alone.

\section{REFERENCES}

1. Anderson JR, Gallup GG Jr. Mirror self-recognition: a review and critique of attempts to promote and engineer self-recognition in primates. Primates. 2015;56(4):317-326.

2. Sinclair S, Russell LB, Hack TF, Kondejewski J, Sawatzky R. Measuring compassion in healthcare: a comprehensive and critical review. Patient. 2017;10(4):389-405.

3. Perez-Bret E, Altisent R, Rocafort J. Definition of compassion in healthcare: a systematic literature review. Int J Palliat Nurs. 2016;22(12):599-606.

4. Mills J, Wand T, Fraser JA. Palliative care professionals' care and compassion for self and others: a narrative review. Int J Palliat Nurs. 2017;23(5):219-229.

5. Cetrano G, Tedeschi F, Rabbi L, et al. How are compassion fatigue, burnout, and compassion satisfaction affected by quality of working life? findings from a survey of mental health staff in Italy. BMC Health Serv Res. 2017;17(1):755.

6. Neff KD. Self-compassion: an alternative conceptualization of a healthy attitude toward oneself. Self-Ident. 2003;2:85-101.

7. Neff KD. The development and validation of a scale to measure self-compassion. Self-Ident. 2003;2:223-250.

8. Sinclair S, Kondejewski J, Raffin-Bouchal S, King-Shier KM, Singh P. Can self-compassion promote healthcare provider wellbeing and compassionate care to others? results of a systematic review. Appl Psychol Health Well Being. 2017;9(2):168-206. 9. Raab K. Mindfulness, self-compassion, and empathy among health care professionals: a review of the literature. J Health Care Chaplain. 2014;20(3):95-108.

10. Dev V, Fernando AT III, Lim AG, Consedine NS. Does selfcompassion mitigate the relationship between burnout and barriers to compassion? A cross-sectional quantitative study of 799 nurses. Int $J$ Nurs Stud. 2018;81:81-88.

11. Montero-Marin J, Zubiaga F, Cereceda M, et al. Burnout subtypes and absence of self-compassion in primary healthcare professionals: a cross-sectional study. PLoS One.

2016;11(6): 0157499.

12. Brown B. Rising Strong: How the Ability to Reset Transforms the Way We Live, Love, Parent, and Lead. New York, NY: Random House US; 2015. 